\title{
Screening of endoscopic microerosions in non-erosive esophagitis by high-definition digestive endoscopy coupled with narrow-band imaging and microerosions analysis by immunohistochemical, pHmetric and histology
}

Frederico S Assirati ${ }^{*}$, Luiz HS Fontes ${ }^{1}$ Carla Pagliari ${ }^{2}$, Luciane K Galo ${ }^{2}$, Wellington LF da Silva ${ }^{2}$, Rafaela BB Pinheiro ${ }^{2}$ Claudio L Hashimoto ${ }^{1}$ and Tomás Navarro-Rodriguez ${ }^{1}$

${ }^{1}$ Department of Gastroenterology, Central Institute of Hospital das Clínicas, University of São Paulo Medical School, São Paulo, Brazil

${ }^{2}$ Department of Pathology, Central Institute of Hospital das Clínicas, University of São Paulo Medical School, São Paulo, Brazil

\begin{abstract}
Introduction: Gastroesophageal reflux disease (GERD) is considered one of the most prevalent digestive diseases in Western countries. In many cases, the symptomatic GERD is linked to a normal upper gastrointestinal endoscopy and new endoscopic techniques to identify the abnormalities are need. The high-definition digestive endoscopy coupled with narrow band imaging (NBI) could achieve a more detailed mucosal evaluation, allowing the identification of distal esophageal microerosions.

Objectives: To validate the presence of distal esophageal microerosions as found in high-definition endoscopy with NBI and the associative pHmetry, histological, immunohistochemical findings of tissue specimens obtained from esophageal biopsies of patients with typical symptoms of GERD.

Methods: A total of 70 participants were enrolled in a prospective, descriptive and cross-sectional study from a gastroenterology outpatient clinic. Endoscopic evaluation was sequentially performed after the pHmetry. Esophageal mucosal biopsies were obtained to perform the histological and immunohistochemical analysis.

Results: From 70 participants, 30/70 (42.9\%) showed mucosal microerosions. Both, pHmetry and histologic score for esophageal mucosa did not showed difference between participants with or without endoscopic microerosions. The quantitative cellular evaluation by immunohistochemistry of the esophageal mucosa was performed in 56/70 (80\%) participants, which 27/56 (48.21\%) showed microerosions. Also, no difference occurred between participants with or without endoscopic microerosions regarding total number of cells immunolabelled and number of cells per tissue area.
\end{abstract}

Conclusions: No difference occurred between the groups of participants with typical symptoms of GERD and with or without esophageal microerosions screened by high-definition digestive endoscopy coupled with NBI regarding pHmetric, histological and immunohistochemical analysis.

Abbreviations: GERD: Gastroesophageal Reflux Disease; GERDNE: Non-Erosive Gastroesophageal Reflux Disease; GERD-E: erosive gastroesophageal reflux disease; IL: Interleukin; LAC: Los Angeles classification; MCP-1: Monocyte Chemoattractant Protein Type 1; NBI: Narrow Band Imaging; PBS: Phosphate Buffered Saline; SCJ: Squamocolumnar Junction; UGE: Upper Gastrointestinal Endoscopy.

\section{Introduction}

Gastroesophageal reflux disease (GERD) has high prevalence in Western countries afflicting around 10-20\% [1,2]. The GERD diagnosis is made through the referred symptoms, associated with diagnostic tests such as upper gastrointestinal endoscopy (UGE), ambulatory monitoring of prolonged $\mathrm{pHmetry}$ or impedance-pH monitoring, and clinical response to antisecretory therapy [3-5]. Approximately $30-50 \%$ of the patient's present erosions or ulcers in the UGE, whereas in the others, there are no clear changes in the mucosa [6].

Until now, the most used reflux esophagitis classification is the Los Angeles Classification (LAC). However, findings of minimal endoscopic changes were included in a modified LAC as follow: $\mathrm{M}$ (erythema without precise demarcation, whitish mucosa and vessel deletion); N (normal appearance) [7]. Regarding to GERD is recommended the use of the LAC in the endoscopic assessment in patients with erosive esophagitis. In patients with grade A esophagitis, there is a need for diagnostic complementation to confirm GERD [8]. The Lyon consensus established standardization in the conduct of the diagnosis of GERD, proposing that only patients with LAC grade C and $\mathrm{D}$, Barrett's esophagus and peptic stenosis would present confirmatory evidence of GERD, and that with LAC grade B the initial drug treatment with proton pump inhibitors would be recommended, but the need for diagnostic complementation for GERD through pHmetry should be highlighted if surgical treatment was need [9]. Finally, nonerosive reflux esophagitis is defined as the presence of reflux-related symptoms in the absence of mucosal lesions at endoscopy. As most

${ }^{*}$ Correspondence to: Frederico S Assirati, Department of Gastroenterology, Central Institute of Hospital das Clínicas, University of São Paulo Medical School, São Paulo, Brazil, Tel: 55(11) 2661 7938; E-mail: fjassirati@yahoo.com.br

key words: esophageal biopsy, gastroesophageal reflux disease, high-definition digestive endoscopy, immunohistochemistry, microerosions, narrow band imaging

Received: January 28, 2020; Accepted: February 14, 2020; Published: February 17,2020 
Assirati FS (2020) Screening of endoscopic microerosions in non-erosive esophagitis by high-definition digestive endoscopy coupled with narrow-band imaging and microerosions analysis by immunohistochemical, pHmetric and histology

patients with reflux-related symptoms have normal UGE, the need of new endoscopic techniques to identify undetected changes in standard endoscopy was evidenced.

Currently, several techniques are being investigated as the high-definition digestive endoscopy modality allowing to identify minimal abnormalities during the endoscopy exam [10], mainly by the acquisition of detailed images of the esophagus [11]. In addition, recently the pathophysiology of GERD was analyzed using histological changes and inflammatory mediators [12]. The knowledge of the action of inflammatory mediators and its interaction with chemical receptors in the esophageal mucosa are fundamental to understand the pathophysiology of GERD and its histological alterations.

Until the early 2000s, GERD would be motivated by a lesion in the stratified squamous epithelium, by the acid and enzymatic content of the gastroduodenal juice. The esophageal mucosa would initially be damaged in its luminal face in the epithelium and would later extend in depth to the submucosal layer, which would result in a proliferative response of the basement membrane. In this traditional model of pathophysiology, hydrogen ions and pepsin would exert a corrosive effect on the mucosal surface, damaging junctional epithelial proteins, consequently generating intramucosal inflammation through an infiltrate containing lymphocytes and neutrophils, which would produce inflammatory mediators and platelet activating factor [13]. On the other hand, in an experimental model of esophagitis in rats, induced by esophagoduodenostomy, it was observed that the epithelial secretion of interleukin 8 (IL-8) was acid induced and was the initial event in GERD, followed by an infiltration of lymphocytes and leukocytes in the submucosa and, later, in the mucosa. This inflammatory response is followed by a proliferative response of the mucosa (basal cell hyperplasia and papilla elongation), possibly implying an immunomodulated pathophysiological model in GERD $[14,15]$.

The presence of IL- 8 , interleukin $1 \beta$ (IL- $1 \beta$ ) and other inflammatory mediators has been investigated in mucosal biopsies and in animal models with GERD. Both interleukins correlate with the intensity of endoscopic and histopathological findings, and their levels decrease with surgical fundoplication to Nissen or acid suppressive therapy with proton pump inhibitors. When the esophageal epithelium comes into contact with the acidic contents of the stomach, the release of inflammatory mediators occurs and represents the initial event in the chemotaxis and activation of the leukocytes in the esophageal mucosa and submucosa [16,17].

In our study we focused the attention on participants with typical symptoms of GERD and we used high-definition digestive endoscopy coupled with narrow band imaging (NBI) to identify esophageal microerosion. Also, esophageal pHmetry, histopathological and immunohistochemical methods were performed. In brief our main aim was to validate the presence and clinical significance of endoscopic microerosions in participants submitted to esophageal mucosal biopsies, with typical symptoms of GERD, using highdefinition digestive endoscopy coupled with NBI, prolonged pHmetry, histopathological and immunohistochemical tests.

\section{Objectives}

The objectives of our study were as follows:

- To validate the presence of distal esophageal microerosions as found in high definition endoscopy with NBI in patients with typical symptoms of GERD.

- To observe changes in prolonged pHmetry in patients with typical symptoms of GERD and distal esophageal microerosions through high definition endoscopy with NBI.

- Toevaluate the significance ofhistological andimmunohistochemical alterations of tissue specimens obtained from esophageal biopsies of patients with typical symptoms of GERD and microerosions in the distal esophagus through high definition endoscopy with NBI.

\section{Methods}

\section{Participants}

We performed a prospective, descriptive and cross-sectional study that invited 90 participants, during a 3-year period, from a gastroenterology outpatient clinic. Seventy patients were enrolled to have the inclusion and exclusion criteria (Figure 1). All participants signed an informed consent term. The study was approved by the Research Ethics Committee of the institution (Cappesq No 940569) and was also recorded in the clinicaltrials.gov database of the National Library of Medicine of the United States (NCT03824431).

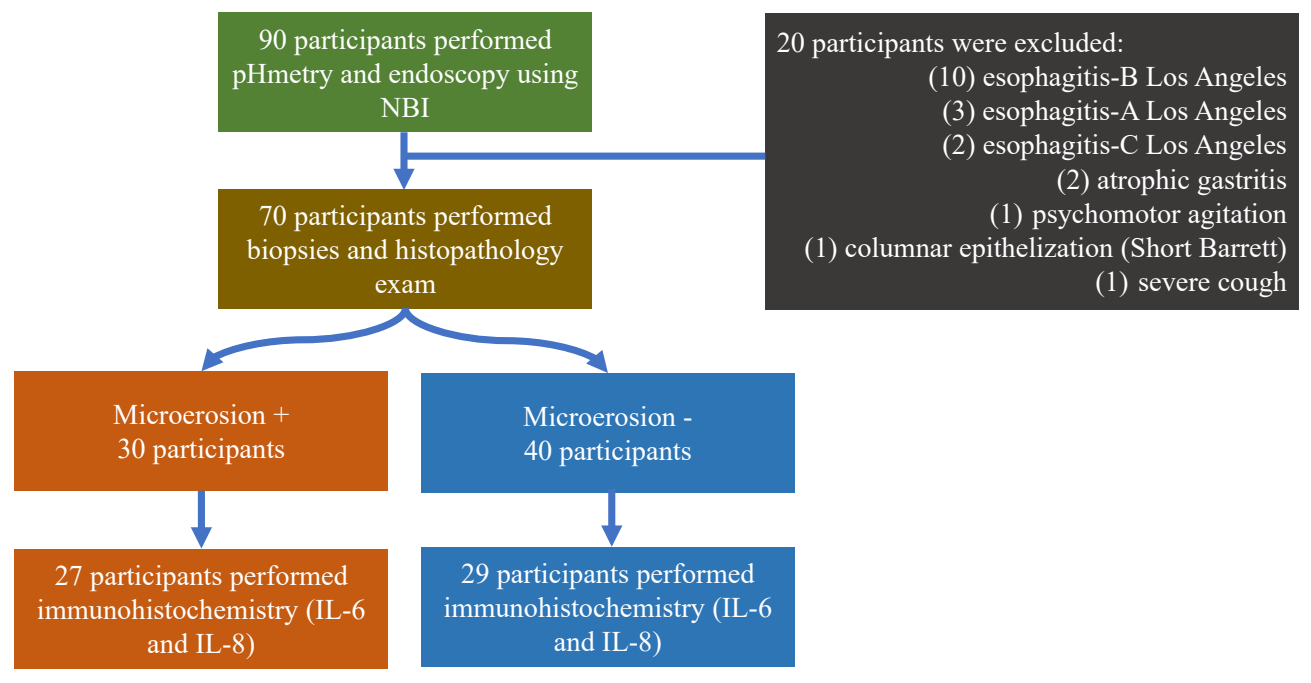

Figure 1. Flux gram 
Assirati FS (2020) Screening of endoscopic microerosions in non-erosive esophagitis by high-definition digestive endoscopy coupled with narrow-band imaging and microerosions analysis by immunohistochemical, pHmetric and histology

The follow inclusion criteria were used: (i) outpatients aged 18 to 70 years; (iii) presence of typical symptoms of GERD, on at least two different days over a week, for a period of at least three consecutive months, and with conventional UGE without esophageal changes, performed in the last 12 months.

The follow exclusion criteria were used (presence of): (i) hiatal hernia; (ii) ulcers of the upper digestive tract; (iii) drugs that interfere with the physiology of the esophagus; (iv) esophago-gastric surgeries; (v) achalasia of the esophagus; (vi) esophagitis (erosive, eosinophilic, medicinal, infectious, non-erosive to conventional endoscopy); (vii) esophageal stricture; (viii) esophageal varices; (ix) clinical situations that prevent more detailed evaluation of the squamocolumnar junction during endoscopy; (x) Barrett's esophagus; (xi) esophageal diverticulum; (xii) atrophic gastritis; (xiii) use of anti-inflammatories in the last 30 days; (xiv) inflammatory and/or immune diseases of the gastrointestinal tract; (xv) diagnosis of infectious diseases in the last 30 days; (xvi) body mass index $>30 \mathrm{~kg} / \mathrm{m}^{2}$; (xvii) pregnant women; (xviii) smoking habit; (xix) use of anticoagulants; $(\mathrm{xx})$ comorbidities that may interfere with esophageal motility; (xxi) use of proton pump inhibitor in the last 7 days.

\section{pHmetric}

The one-channel pHmetry probe was introduced and positioned at $5 \mathrm{~cm}$ from the upper border of the lower sphincter, based on an esophageal manometry. The prolonged pHmetric evaluation in the distal esophagus was based on the percentage of the total time of the exam with $\mathrm{pH}<4$ at supine, orthostatic and combined positions, in association with symptoms, and the DeMeester score. The pathological pHmetry was considered when the percentage of the total examination time with $\mathrm{pH}<4$ was greater than $4.5 \%$ (orthostatic position: exposure time greater than $8.4 \%$; supine position: exposure time greater than $3.5 \%)[18,19]$. The DeMeester composite score was evaluated under two aspects: (i) pathological $\mathrm{pH}$ parameter when it exceeded 14.7; (ii) no pathological $\mathrm{pH}$ parameter, regardless of its value [20].

The correlation between symptoms and $\mathrm{pH}<4$ was evaluated through the index of symptoms association probability. Patients who presented symptoms association probability $>95 \%$ and total acid exposure time with $\mathrm{pH}<4$ greater than $4.5 \%$ were considered as having hypersensitive esophagus $[21,22]$.

The prolonged pHmetry probe was removed in the following day and sequentially performed high-definition digestive endoscopy coupled with NBI.

\section{Endoscopic}

Initially, during the endoscopic examination (Evis Excera IIGIF-H180, Olympus Corporation, Shinjuku-ku, Tokyo, Japan) using white light, the esophagus was evaluated as a whole, as well as the presence of obvious erosions. If an obvious erosion occurred, the patient was excluded from the study, but digestive endoscopy was completed routinely until the end. Individuals who did not have obvious erosions during endoscopy with white light, had a more detailed circumferential verification of the entire squamocolumnar junction (SCJ) using NBI and digital zoom, coupled with a transparent cap on the tip of the endoscopy, in order to verify the presence of microerosions (Figure 2A-2C).

Then, the usual evaluation was done with white light of the stomach and duodenum. Subsequently, the biopsies were performed, and four fragments were obtained in the distal esophagus to $2 \mathrm{~cm}$ of the SCJ, next to the inferior quadrant seen in the endoscopic monitor (Figure2D). To obtain

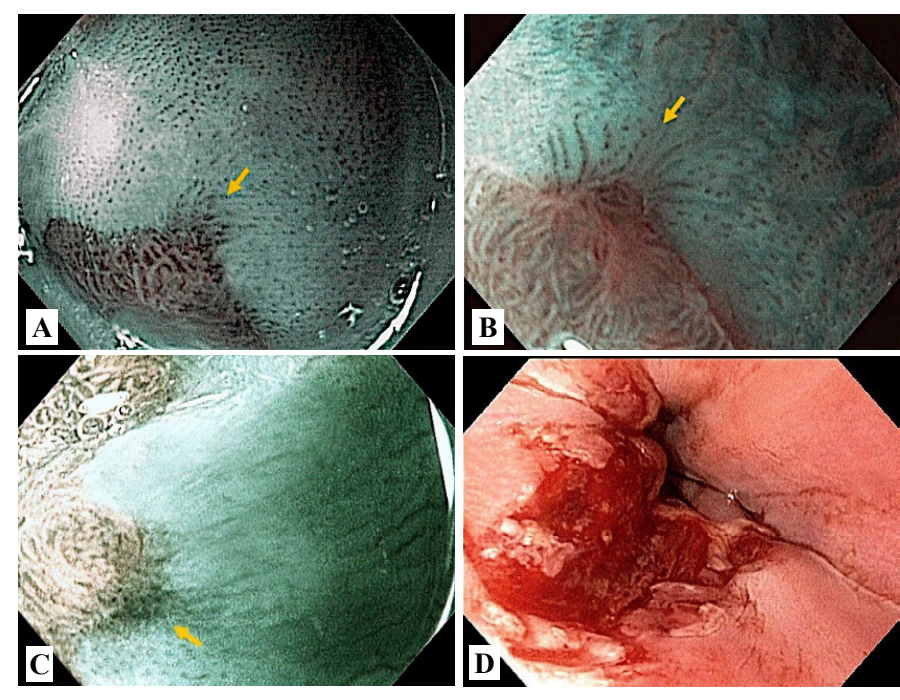

Figure 2. A, B and C. Endoscopic microerosions; D. Post esophageal biopsies

the tissue samples, Radial Jaw $4^{\circ}$ (Boston Scientific, Marlborough, MA) was used to have greater capacity to obtain representative fragments, both in extent and in depth [23].

\section{Histopathologic analysis}

The fragments of the esophageal biopsies were fixed in a $10 \%$ formalin buffer solution and embedded in paraffin for histopathological analysis. On average, four cuts of each fragment were performed and the best one (in terms of orientation and dye uptake) was selected for analysis.

The fragments obtained in the biopsies were fixed in buffered formalin for about 24 hs and processed into paraffin embedding. Histological sections of the paraffin blocks were made with a thickness of $3 \mu \mathrm{m}$ and stained with hematoxylin and eosin stain.

The microscope used in the evaluation was the Eclipse E200 model (Nikon, Minato-ku, Tokyo, Japan). All histological sections available on the histological slide of each case were initially evaluated in the small and medium magnifications $(4 \mathrm{x}$ and $10 \mathrm{x})$ in order to identify the area with maximum morphological change. This area was then evaluated semi-quantitatively, in the medium and large magnifications (10x and 40x), in relation to (Figure 3): (i) basal layer thickness $[(0)<$ $15 \%$; (i) $15-30 \%$; (2) > 30\%); (ii) lamina propria elongation of papillae [(0) < 50\%; (1) 50-75\%; (2) > 75\%]; (iii) dilation intercellular space [(0) absent; (1) mild; (2) marked]; (iv) intraepithelial eosinophilic inflammatory infiltrate [(0) absent; (1) one to two eosinophils, in one large increase field (40x); (2) > two eosinophils in one large increase field]; (v) intraepithelial neutrophilic infiltrate [(0) absent; (1) one to two eosinophils, in one high-magnification field; (2) > two eosinophils in one high-magnification field]; (vi) intraepithelial lymphocytic inflammatory infiltrate $[(0)<10$ lymphocytes in one large increase field; (1) 10 to 30 lymphocytes in one large increase field; (2) > 30 lymphocytes in one large increase field]; (vii) erosion [(0) absent; (2) present) $[24,25]$. A final score for each biopsy was constructed by adding the scores of each parameter, ranging from 0 to 14 .

\section{Immunohistochemical analysis}

The immunohistochemical methodology was adjusted to detect interleukins in paraffin. The assertion of their operation is the positive controls that always accompany each reaction and the use of the kits, performed according to the manufacturer's recommendations [26]. 
Assirati FS (2020) Screening of endoscopic microerosions in non-erosive esophagitis by high-definition digestive endoscopy coupled with narrow-band imaging and microerosions analysis by immunohistochemical, pHmetric and histology

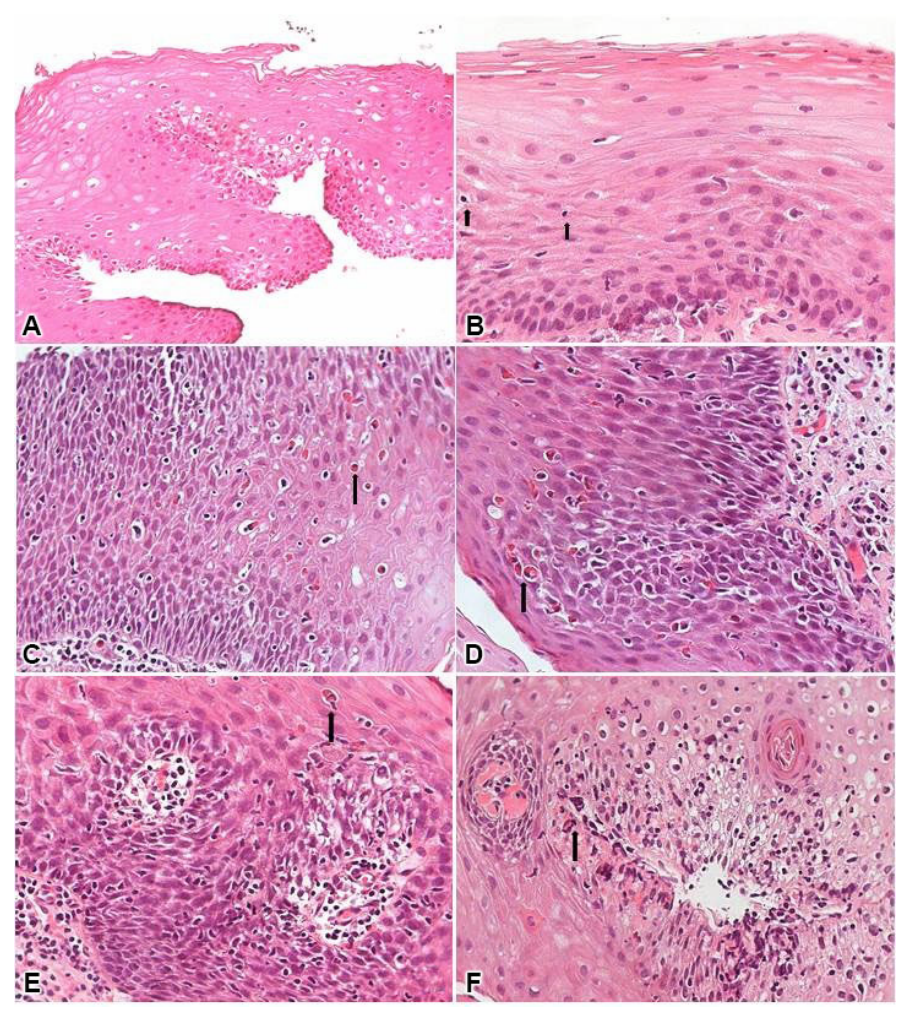

Figure 3. A. Presence of immunolabelled cells in the analysis of IL-6 in participants with microerosions; B. Presence of immunolabelled cells in the analysis of ILi8 in participants with microerosions

After two incubations of dewaxing the histological sections with xylol (20 mins and 10 mins, respectively) and hydration of the sections in ethanol (100\%, 95\% and 70\%), endogenous peroxidase blockade was performed with three passages of 10 mins each, in 3\% hydrogen peroxide solution (10 volumes) in a darkroom. The slides were washed in running water for five mins, distilled water and phosphate buffered saline (PBS) pH 7.4.

The antigenic exposure was done in a water bath with Tris-EDTA solution (Hydroxymethyl-Aminomethane/ethylenediaminetetraacetic acid) $\mathrm{pH} 9.0$ for 20 mins at $95^{\circ} \mathrm{C}$ in water bath (Dako S236784-2, Agilent, Santa Clara, CA). Wash under running water, distilled water and in PBS buffer for five mins. Incubation was carried out with $10 \%$ skimmed milk in distilled water for 30 mins at room temperature.

Incubation with the primary antibody [goat anti-IL-8 immunoglobulin (AF-208-NA; 1:100); anti-interleukin 6 (IL-6) mouse immunoglobulin (NCL-L-IL6; 1:30)] was diluted in bovine serum albumin $1 \%$, during an over-night period at $4{ }^{\circ} \mathrm{C}$. Then washed in PBS for five mins and washed in PBS $+0.1 \%$ saponin (1 mg saponin to 100 $\mathrm{mL}$ PBS pH 7.4) for 10 mins and incubated with the secondary antibody of the labeled streptavidin-biotin kit (Dako, K690) for 45 mins at $37^{\circ} \mathrm{C}$. Thereafter, further washing in PBS for five mins, PBS $+10 \%$ saponin for 10 mins and PBS buffer.

The incubation with streptavidin biotin complex of labeled streptavidin-biotin was followed for 30 mins at $37^{\circ} \mathrm{C}$. Wash in PBS for 10 mins and revealed the reaction with 3,3 diaminobenzidine solution. The DAB was prepared by diluting $45 \mathrm{mg}$ of this chromogen in $100 \mathrm{~mL}$ of PBS buffer $\mathrm{pH} 7.4$ and adding $1,200 \mu \mathrm{L}$ of $3 \%$ hydrogen peroxide.

The intensity of the immunostaining was made under the optical microscope, in known positive controls that accompany each reaction or IL-6 and IL-8; histological sections of the lung were used.
After the development of the reaction, the sections were washed in running water and contracted for one min in hematoxylin. Then, they were rinsed again in running water and dehydrated in increasing ethanol sequence, and the blades were assembled with Permount resin [27,28].

\section{Quantification of immunohistochemical reactions}

The slides prepared with the immunohistochemical techniques were submitted to quantitative analysis considering the area of the fields photographed according to standard stipulated by the pathologists, evaluating the entire extent of the tissue fixed in the slide, in a photomicroscope with a $40 \mathrm{X}$ objective.

The fields for analysis were obtained by photographing the esophageal mucosa that was the histological region of interest. The AxioCam MR3 camera was coupled to the microscope (Zeiss', Jena, Germany) and the AxioVision 4.8 (Zeiss ) program in 40X objective. The analysis were continued using the Image-Pro ${ }^{\circ}$ Plus 4 program (Rockville, MA), where the cells were counted immunoreacted with the anti-IL- 8 and anti-IL- 6 antibodies and the field area was measured. All areas were obtained in $\mu \mathrm{m}^{2}$.

The data was shown as number of cells quantified in each slide with the studied field area, obtaining a relation in number of cells by the measured area $\left(\mu \mathrm{m}^{2}\right)$.

\section{Statistical analysis}

The statistical analysis was done using the stratification according the diagnosis of the microerosions. The descriptive analysis is shown as 95\% confidence interval ( $95 \% \mathrm{CI})$, mean, standard deviation, median, $25^{\text {th }}$ percentile (P25) and $75^{\text {th }}$ (P75). The Kolmogorov-Smirnov test was used to evaluate the normality. In brief, the follow statistical tests were applied: Mann-Whitney test, chi-square test or Fischer's exact test. An alpha error of 0.05 was adopted in all statistical tests. The Statistical Package for the Social Sciences was used to perform the statistical analysis (IBM Corp. Released 2017. IBM SPSS Statistics for Windows, Version 25.0. Armonk, NY: IBM Corp).

\section{Results}

\section{Population}

Seventy patients were enrolled, of which 30/70 (42.9\%) presented microerosions. No difference between the proportion of male and female participants occurred regarding the diagnosis of microerosions (male without microerosions $25.0 \%$ (95\%CI: $13.6 \%$ to $39.8 \%$ ) versus male with microerosions $16.7 \%$ (95\%CI: $6.7 \%$ to $32.7 \%$ ). The mean age was $47.9 \pm 11.26$ years (18 to 70 years). Also, mean age in both groups regarding microerosions was equal (participants with microerosion $50.3 \pm 10.4$ years and without microerosion $46.1 \pm 11.6$ years) ( $P$-value $=0.061$ ).

\section{Prolonged esophageal pHmetry}

At the prolonged pHmetry, participants with microerosion presented slightly higher values of the acid and extended acid refluxes in the distal sensor, and in the DeMeester score, but these results were not statistically significant (Table 1).

Regarding the diagnoses of the prolonged pHmetry, 52/62 (83.9\%) of the participants presented normal $\mathrm{pH}$ without to consider the DeMeester score. Using the score, two participants were reclassified $50 / 62(80.6 \%)$. The presence of microerosions occurred in $58.3 \%$ (95\%CI: $31.2 \%$ to $82.0 \%$ ) of the pathological ones in the first case and, in $50.0 \%$ (95\%CI: $25.9 \%$ to $74.1 \%$ ), in the second case (Table 2 ). 
Assirati FS (2020) Screening of endoscopic microerosions in non-erosive esophagitis by high-definition digestive endoscopy coupled with narrow-band imaging and microerosions analysis by immunohistochemical, pHmetric and histology

Table 1. Association of esophageal pHmetry parameters and immunohistochemical analysis between participants with gastroesophageal reflux disease symptons, with or without microerosions

\begin{tabular}{|c|c|c|c|c|c|}
\hline \multirow{2}{*}{ pHmetry parameters } & \multicolumn{2}{|c|}{ Microerosions - } & \multicolumn{2}{|c|}{ Microerosions + } & \multirow{2}{*}{$P$-value } \\
\hline & Mean \pm SD & Median (IIQ) & Mean \pm SD & Median (IIQ) & \\
\hline $\mathrm{N}^{o}$ Total distal acid reflux ${ }^{\mathrm{b}}$ & $14.0 \pm 12.4$ & $10.0(5.0-20.0)$ & $19.4 \pm 15.4$ & $18.0(6.0-29.0)$ & 0.149 \\
\hline $\mathrm{N}^{\circ}$ Extended distal acid refluxes & $1.3 \pm 2.5$ & $0(0-2.0)$ & $1.5 \pm 2.0$ & $1.0(0-2.0)$ & 0.452 \\
\hline Total time fraction distal acid reflux ${ }^{\mathbf{c}}$ & $2.0 \pm 3.0$ & $1.0(0-2.0)$ & $3.0 \pm 3.0$ & $2.0(0-4.0)$ & 0.215 \\
\hline Orthostatic distal acid reflux fraction time & $3.0 \pm 3.0$ & $1.0(0-3.0)$ & $3.0 \pm 3.0$ & $3.0(1.0-4.0)$ & 0.355 \\
\hline Supine distal acid reflux fraction time & $1.0 \pm 3.0$ & $0(0-1.0)$ & $3.0 \pm 5.0$ & $0(0-5.0)$ & 0.598 \\
\hline DeMeester score & $10.3 \pm 11.2$ & $8.1(2.8-11.7)$ & $12.5 \pm 12.1$ & $7.7(2.6-20.5)$ & 0.505 \\
\hline \multicolumn{6}{|l|}{ Immunohistochemical analysis } \\
\hline Interleukin-6 & Mean (SD) & Median (IIQ) & Mean (SD) & Median (IIQ) & $P$-value \\
\hline $\mathrm{N}^{\circ}$. total cells ${ }^{\mathrm{d}}$ & $0.10 \pm 0.50$ & $0(0-0)$ & $1.40 \pm 3.70$ & $0(0-0)$ & 0.095 \\
\hline Total area $\left(\mu \mathrm{m}^{2}\right)$ & $0.22 \pm 0.04$ & $0.22(0.18-0.26)$ & $0.23 \pm 0.04$ & $0.22(0.21-0.26)$ & 0.259 \\
\hline $\mathrm{N}^{\mathrm{o}}$. cells/area $\left(\mu \mathrm{m}^{2}\right)^{\mathrm{e}}$ & $0.67 \pm 2.58$ & $0(0-0)$ & $6.57 \pm 17.80$ & $0(0-0)$. & 0.095 \\
\hline Interleukin-8 & Mean (SD) & Median (IIQ) & Mean (SD) & Median (IIQ) & $P$-value \\
\hline $\mathrm{N}^{\mathrm{o}}$. total cells $\mathrm{s}^{\mathrm{f}}$ & $0(1.00)$ & $0(0-0)$ & $0(1.00)$ & $0(0-0)$ & 0,351 \\
\hline Total area $\left(\mu \mathrm{m}^{2}\right)$ & $0.22(0.03)$ & $0.22(0.21-0.26)$ & $0.22(0.03)$ & $0.22(0.21-0.26)$ & 0,946 \\
\hline $\mathrm{N}^{o}$. cells/area $\left(\mu \mathrm{m}^{2}\right)^{\mathrm{g}}$ & $0.54(2.55)$ & $0(0-0)$ & $1.26(3.70)$ & $0(0-0)$ & 0,344 \\
\hline
\end{tabular}

${ }^{\mathrm{a}}: P$-value based on the Mann-Whitney test. Alpha $=0.05$; $\left.{ }^{\mathrm{b}} 1-\beta=0.680\right) ; \mathrm{c}: 1-\beta=0.890$; ${ }^{\mathrm{d}} 1-\beta=0.780 ;{ }^{\mathrm{e}} 1-\beta=0.760 ;{ }^{\mathrm{f}} 1-\beta=0.564 ;{ }^{\mathrm{g}:} 1-\beta=0.578$.

Table 2. Association of the pHmetry and histological diagnosis, between participants with gastroesophageal reflux disease symptons, with or without microerosions

\begin{tabular}{|c|c|c|c|c|c|c|c|c|c|}
\hline \multirow{3}{*}{ Parameters } & \multicolumn{4}{|c|}{ Microerosions - } & \multicolumn{4}{|c|}{ Microerosions + } & \multirow[b]{3}{*}{$P$-value } \\
\hline & \multirow{2}{*}{$\mathbf{N}$} & \multirow{2}{*}{$\%$} & \multicolumn{2}{|c|}{$95 \% \mathrm{CI}$} & \multirow{2}{*}{$\mathbf{N}$} & \multirow{2}{*}{$\%$} & \multicolumn{2}{|c|}{$95 \% \mathrm{CI}$} & \\
\hline & & & Inferior & Superior & & & Inferior & Superior & \\
\hline \multicolumn{10}{|l|}{ Without DeMeester ${ }^{\mathrm{b}}$} \\
\hline Distal pathological $\mathrm{pH}$ & 5 & $41.7 \%$ & $18.0 \%$ & $68.8 \%$ & 7 & 58.3 & $31.2 \%$ & $82.0 \%$ & \multirow{2}{*}{0.400} \\
\hline Distal normal pH & 30 & $60.0 \%$ & $46.2 \%$ & $72.7 \%$ & 20 & 40.0 & $27.3 \%$ & $53.8 \%$ & \\
\hline \multicolumn{10}{|l|}{ With DeMeester ${ }^{c}$} \\
\hline Distal pathological $\mathrm{pH}$ & 7 & $50.0 \%$ & $25.9 \%$ & $74.1 \%$ & 7 & 50.0 & $25.9 \%$ & $74.1 \%$ & \multirow{2}{*}{0.410} \\
\hline Distal normal pH & 28 & $58.3 \%$ & $44.2 \%$ & $71.5 \%$ & 20 & 41.7 & $28.5 \%$ & $55.8 \%$ & \\
\hline \multicolumn{10}{|l|}{ Basal layer hyperplasia } \\
\hline 0 & 26 & $65.0 \%$ & $49.6 \%$ & $78.3 \%$ & 22 & 73.3 & $55.9 \%$ & $86.5 \%$ & \multirow{2}{*}{0.316} \\
\hline 1 & 14 & $35.0 \%$ & $21.7 \%$ & $50.4 \%$ & 8 & 26.7 & $13.5 \%$ & $44.1 \%$ & \\
\hline \multicolumn{10}{|l|}{ Papillary elongation } \\
\hline 0 & 32 & $80.0 \%$ & $65.8 \%$ & $90.1 \%$ & 22 & 73.3 & $55.9 \%$ & $86.5 \%$ & \multirow{2}{*}{0.354} \\
\hline 1 & 8 & $20.0 \%$ & $9.9 \%$ & $34.2 \%$ & 8 & 26.7 & $13.5 \%$ & $44.1 \%$ & \\
\hline \multicolumn{10}{|c|}{ Intraepithelial neutrophils } \\
\hline 0 & 38 & $95.0 \%$ & $84.9 \%$ & $98.9 \%$ & 26 & 86.7 & $71.3 \%$ & $95.3 \%$ & \multirow{3}{*}{0.146} \\
\hline 1 & 1 & $2.5 \%$ & $0.3 \%$ & $11.1 \%$ & 1 & 3.3 & $0.4 \%$ & $14.5 \%$ & \\
\hline 2 & 1 & $2.5 \%$ & $0.3 \%$ & $11.1 \%$ & 3 & 10.0 & $2.9 \%$ & $24.3 \%$ & \\
\hline \multicolumn{10}{|c|}{ Intraepithelial eosinophils } \\
\hline 0 & 37 & $92.5 \%$ & $81.3 \%$ & $97.8 \%$ & 23 & 76.7 & $59.6 \%$ & $88.9 \%$ & \multirow{3}{*}{0.162} \\
\hline 1 & 2 & $5.0 \%$ & $1.1 \%$ & $15.1 \%$ & 4 & 13.3 & $4.7 \%$ & $28.7 \%$ & \\
\hline 2 & 1 & $2.5 \%$ & $0.3 \%$ & $11.1 \%$ & 3 & 10.0 & $2.9 \%$ & $24.3 \%$ & \\
\hline \multicolumn{10}{|c|}{ Intraepithelial lymphocytes } \\
\hline 0 & 29 & $72.5 \%$ & $57.5 \%$ & $84.4 \%$ & 24 & 80.0 & $63.3 \%$ & $91.2 \%$ & \multirow{3}{*}{0.750} \\
\hline 1 & 8 & $20.0 \%$ & $9.9 \%$ & $34.2 \%$ & 5 & 16.7 & $6.7 \%$ & $32.7 \%$ & \\
\hline 2 & 3 & $7.5 \%$ & $2.2 \%$ & $18.7 \%$ & 1 & 3.3 & $0.4 \%$ & $14.5 \%$ & \\
\hline \multicolumn{10}{|c|}{ Dilatated intercellular space ${ }^{\mathrm{d}}$} \\
\hline 0 & 2 & $5.0 \%$ & $1.1 \%$ & $15.1 \%$ & 2 & 6.7 & $1.4 \%$ & $19.7 \%$ & \multirow{3}{*}{0.658} \\
\hline 1 & 28 & $70.0 \%$ & $54.8 \%$ & $82.4 \%$ & 18 & 60.0 & $42.2 \%$ & $76.0 \%$ & \\
\hline 2 & 10 & $25.0 \%$ & $13.6 \%$ & $39.8 \%$ & 10 & 33.3 & $18.6 \%$ & $51.1 \%$ & \\
\hline
\end{tabular}

a: $P$-value based on the chi-square test or or Fisher's exact test; ${ }^{\mathrm{b}}:$ not considering the DeMeester score as one of the parameters of pathological $\mathrm{pHmetry}, 1-\beta=0.691 ;{ }^{\mathrm{c}}$ : considering the DeMeester score as one of the parameters of pathological pHmetry, $1-\beta=0.702 ;{ }^{\mathrm{d}}: 1-\beta=0.396$. 
Assirati FS (2020) Screening of endoscopic microerosions in non-erosive esophagitis by high-definition digestive endoscopy coupled with narrow-band imaging and microerosions analysis by immunohistochemical, pHmetric and histology

Other diagnoses occurred in low percentages and with similar distribution between groups, including absence of reflux $6 / 70(8.5 \%)$ and symptomatic distal physiologic acid reflux 2/70 (2.8\%).

The diagnostic parameters of positive microerosions in predicting pathological $\mathrm{pH}$ monitoring considering or not DeMeester score were evaluated. The accuracy, sensitivity and specificity were, respectively, 0.597 (95\%CI: 0.464 to 0.719 ), 0.583 (95\%CI: 0.277 to 0.848 ) and 0.600 (95\%CI: 0.452 to 0.736 ) without considering the DeMeester score as one of the parameters of pathological pHmetry. On the other hand, considering the DeMeester score the accuracy, sensitivity and specificity were, respectively, 0.565 ( $95 \% \mathrm{CI}: 0.433$ to 0.690 ), 0.500 (95\%CI: 0.230 to 0.770 ) and 0.583 (95\%CI: 0.432 to 0.724 ) using the DeMeester score (Table 3).

\section{Histopathology}

In the participants with microerosion, the histological score was $2.6 \pm 1.9$ and, in the participants without microerosion was 2.3 $\pm 1.9(P$-value $=0.532)$. No difference occurred between the groups for dilation of intercellular spaces $(P$-value $=0.658)$. Both, normal or distal pathological pHmetry and histological parameters did not differ according the diagnosis of microerosions (Tables 2 and 4).

\section{Immunohistochemistry}

In our study, it was possible to quantitate the cells by means of immunohistochemistry of the esophageal mucosa in $56 / 70(80 \%)$ of the participants [ $48,2 \%$ (95\%CI: $35.50 \%$ to $61.10 \%$ ) with microerosions and $51.79 \%$ (95\%CI: $38.9 \%$ to $64.5 \%$ ) without microerosions], because the lack of enough tissue to perform the analysis. Regarding the quantification of cells immunolabelled with the anti-IL6 antibody, only $8 / 56$ (14.2\%) participants had at least one labeled cell.

Participants with microerosions showed $1.40 \pm 3.70$ cells and without microerosions $0.10 \pm 0.50$ cells $(\mathrm{P}$-value $=0.095)$. The total

Table 3. Diagnostic parameters of positive microerosions in predicting pathological $\mathrm{pH}$ monitoring considering or not DeMeester score in participants with gastroesophageal reflux disease symptoms, with or without microerosions.

\begin{tabular}{|l|c|c|c|c|c|c|}
\hline & \multicolumn{3}{|c|}{ Without DeMeester } & \multicolumn{3}{c|}{ With DeMeester } \\
\hline & \multirow{2}{*}{ Estimate } & \multicolumn{2}{|c|}{$\mathbf{9 5 \% C I}$} & \multirow{2}{*}{ Estimate } & \multicolumn{2}{c|}{ 95\%CI } \\
\cline { 3 - 4 } & & Inferior & Superior & & Inferior & Superior \\
\hline Sensitivity & 0.583 & 0.277 & 0.848 & 0.500 & 0.230 & 0.770 \\
\hline Specificity & 0.600 & 0.452 & 0.736 & 0.583 & 0.432 & 0.724 \\
\hline False negative rate & 0.417 & 0.152 & 0.723 & 0.500 & 0.230 & 0.770 \\
\hline False positive rate & 0.400 & 0.264 & 0.548 & 0.417 & 0.276 & 0.568 \\
\hline Predictive positive value & 0.259 & 0.111 & 0.463 & 0.259 & 0.111 & 0.463 \\
\hline Predictive negative value & 0.857 & 0.697 & 0.952 & 0.800 & 0.631 & 0.916 \\
\hline Accuracy & 0.597 & 0.464 & 0.719 & 0.565 & 0.433 & 0.690 \\
\hline Likehood ratio positive test & 1.458 & 0.811 & 2.621 & 1.200 & 0.644 & 2.234 \\
\hline Likehood ratio negative test & 0.694 & 0.343 & 1.408 & 0.857 & 0.482 & 1.524 \\
\hline
\end{tabular}

Table 4. Histological score stratified by normal or distal pathological pHmetry

\begin{tabular}{|c|c|c|c|c|c|c|c|}
\hline \multirow{2}{*}{ Parameters } & \multicolumn{3}{|c|}{ Microerosions - } & \multicolumn{3}{|c|}{ Microerosions + } & \multirow{2}{*}{$P$-value ${ }^{\text {a }}$} \\
\hline & Median & $\mathbf{P 2 5}$ & P75 & Median & $\mathbf{P 2 5}$ & P75 & \\
\hline \multicolumn{8}{|l|}{ Without DeMeester ${ }^{b}$} \\
\hline Distal normal pH & 2 & 1 & 3 & 2 & 1 & 4 & 0.947 \\
\hline Distal pathological pH & 1 & 1 & 4 & 2 & 1 & 4 & 0.388 \\
\hline \multicolumn{8}{|l|}{ With DeMeester ${ }^{c}$} \\
\hline Distal normal pH & 2 & 1 & 3 & 2 & 1 & 4 & 0.388 \\
\hline Distal pathological pH & 1 & 1 & 5 & 2 & 1 & 3 & 0.998 \\
\hline
\end{tabular}

a: $P$-value based on the Mann-Whitney test; ${ }^{\text {b}}$ : not considering the DeMeester score as one of the parameters of pathological pHmetry; ${ }^{c}$ : considering the DeMeester score as one of the parameters of pathological pHmetry.

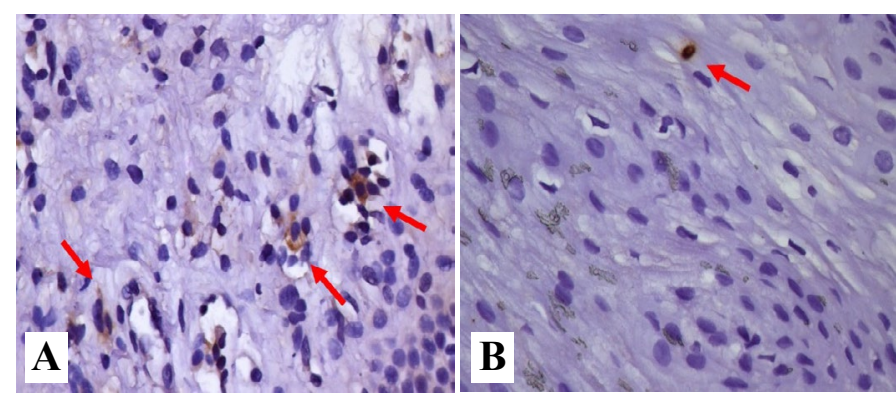

Figure 4. Inflammatory reaction in the esophageal epithelium. A and B. normal epithelium. Rare lymphocytes are shown (short arrow); C and D. Epithelium and lamina propria. Rare eosinophils are shown (long arrow); E and F. Acanthosis of the epithelium and basal layer hyperplasia. Stretching and congestion of papillae and widening of intercellular spaces. Hematoxylin and eosin were used to identify the cells.

area $(\mu \mathrm{m})$ and no of cells/area $\left(\mu \mathrm{m}^{2}\right)$ did not have differences between groups (Table 1).

Using cells immunolabelled with the anti-IL8 antibody, it was verified that $6 / 56(10.7 \%)$ of the participants had at least one labeled cell. But, none of the other parameters evaluated showed statistically differences between the both groups (Table 1).

Figure 4 illustrate the immunolabelled cells by IL- 6 and IL- 8 in participants with microerosions.

\section{Discussion}

The GERD symptoms are the most frequent indication to use UGE, mainly in Western countries; also, using UGE we can screen nonerosive GERD (GERD-NE), erosive GERD (GERD-E) and Barrett's Esophagus. It is currently believed that the progression from GERDNE to GERD-E is uncommon ( 30\%) [29]. Also, in order to evaluate the pathophysiology of GERD, it was evident the need for studies to identify early factors from symptomatic patients. In this context, we enrolled participants with typical symptoms of GERD, exploring the presence of microerosions in high-definition digestive endoscopy coupled with NBI, esophageal pHmetry, as well as biopsies in the distal esophagus was done for histological and immunohistochemical analysis.

In a Taiwanese study with typical symptoms of GERD, pHmetric parameters were compared between participants with GERD-NE and minimal endoscopic changes in the distal esophagus and GERD-NE without minimal endoscopic changes, but no difference occurred between the both groups. However, patients with minimal endoscopic changes in the distal esophagus had a lower index of positive correlation of symptoms in pHmetry; then minimal endoscopic alterations would have little influence on the pathophysiological evolution of GERD. Thus, the presence of symptoms in patients with minimal endoscopic alterations might not be related to acid reflux [30]. In addition, other study enrolled patients with symptomatic GERD that were stratified according to endoscopic findings in groups who underwent pHmetry: (i) mild to moderate esophagitis (LAC grades A and B); (ii) severe or complicated esophagitis (LAC grades C, D and Barrett's esophagus); (iii) asymptomatic controls with normal exams. Again, no significant difference between the patients with GERD-NE and patients with mild to moderate esophagitis occurred in the pHmetry. On the other hand, there was a significant difference in pHmetry parameters between patients with GERD-NE and asymptomatic controls [31]. In our data, both pHmetry parameters as well as the frequency of diagnosis of normal distal pHmetry and pathological pHmetry in the distal sensor did not show statistical difference between the groups with and without 
Assirati FS (2020) Screening of endoscopic microerosions in non-erosive esophagitis by high-definition digestive endoscopy coupled with narrow-band imaging and microerosions analysis by immunohistochemical, pHmetric and histology

microerosions. Also, we evaluated the DeMeester score under two aspects: (i) considering it as one of the pathological pH parameters and (ii) not considering it as a pathological $\mathrm{pH}$ parameter [32].

A comparative analysis of the parameters observed in our study with that performed by Tseng [33], referring to the sensitivity, specificity and accuracy regarding the use of high-definition digestive endoscopy coupled with NBI in predicting the diagnosis of GERD (pathological $\mathrm{pH}$ ) showed slightly higher level of sensitivity in our study to identify GERD when the DeMeester score is not considered. However, due to the increased sensitivity of the method, there is a greater possibility of identifying patients who do not actually have GERD (lower specificity).

At the literature is shown a poor concordance among symptoms, endoscopic findings and histology findings, then routine histological examination of the mucosa in GERD was not recommended [34]. The endoscopist would be unable to predict the histological result when minimal changes were observed in the esophageal mucosa. But our study represents to a certain extent a complementation in the investigation of endoscopic alterations using current technological resources (highdefinition digestive endoscopy coupled with NBI) investigating also the participation of inflammatory factors in the establishment of the association of microerosions as an early finding in the evolution of GERD. In the present study, biopsies were important in order to obtain a tissue substrate for morphological and immunohistochemical evaluation in an attempt to define its etiopathogenesis and significance in the evolution of GERD.

High-definition digestive endoscopy coupled with NBI theoretically allow a reclassification of patients with GERD, who initially had a normal examination of the esophagus and who subsequently had erosion identification (LAC grade A) [35]. The identification of microerosions, makes us think of a reclassification of these patients analyzed to LAC grade A, since this classification is already well known and consecrated.

A method to obtain esophageal tissue samples with subepithelial layer representativeness was described in eosinophilic patients using high capacity biopsy tweezers tissue [23]. In our study, deeper strata of the esophageal epithelium were obtained, including the lamina propria. In the literature, there were no evaluations in patients with GERD symptoms and minimal endoscopic alterations using high capacity endoscopic tweezers in order to obtain tissue from the epithelial lamina propria for evaluation of inflammatory mediators.

Previously, a study using microscopic esophagitis in patients with GERD symptoms stratified individuals into five groups through UGE and impedance-pH monitoring. All patients underwent endoscopic biopsies of the distal esophageal mucosa and stratified analysis using a histological score. The prevalence of microscopic esophagitis occurred in GERD-E (95\%), GERD-NE (77\%), hypersensitive esophagus (65\%), functional heartburn (13\%) and asymptomatic controls (15\%); then, microscopic esophagitis could distinguish patients with GERD from individuals with functional heartburn [25]. However, the evaluation of histology in the diagnosis through routine GERD biopsies is not recommended [3].

Another investigation using high-definition digestive endoscopy coupled with NBI, evaluated histology in the distal esophagus of patients with GERD. It was evidenced that none of the findings verified was significant in relation to the characteristic histological alterations of GERD. The study revealed histological changes compatible with GERD in $70.4 \%$ of the patients [36]
The effort to identify minimal endoscopic changes in GERD would only make sense if there was a significant change in the course of treatment or if their presence could prevent more invasive or uncomfortable exams (e.g. pHmetry or 24-hour impedance-pHmetry). The minimal endoscopic alterations do not seem to predict which patients would be at higher risk of progression to adenocarcinoma, nor would they predict a clinical or surgical response in GERD [37].

Expression of IL-8 mRNA is correlated with the degree of endoscopic esophagitis or infiltration of inflammatory cells, but not with the patients' symptoms. The expression of IL-8 mRNA for GERDNE was detected at lower levels than in patients with GERD-E, but at higher levels than in patients with normal mucosa to UGE. The IL-8 in the esophageal mucosa may be involved in the pathogenesis of esophageal inflammation including non-erosive form [16].

The level of cytokines in the esophageal mucosa in the gastroesophageal reflux was evaluated and, both IL-8 and MCP1 (monocyte chemoattractant protein type 1 ) were elevated in the esophageal mucosa in GERD. The IL-8 levels correlated with the intensity of inflammation and IL-1 $\beta$ levels. Basal mucosa layer hyperplasia and papillary elongation were both associated with a higher level of IL- 8 and MCP-1. The local production of cytokines may be involved in the onset and progression of reflux esophagitis $[38,39]$.

In an evaluation of the IL- $1 \beta$ and IL-8 expression in the gastroesophageal mucosa of patients with GERD and controls, with respect to histomorphology parameters with erosive and non-erosive esophagitis, patients with GERD presented higher levels of IL-1 $\beta$ and IL-8. Also, histological analysis demonstrated a progressive increase in intercellular space dilatation and the degree of basement membrane hyperplasia when compared to controls. Erosive and nonerosive esophagitis are associated with the induction of IL- $1 \beta$ and IL-8 proinflammatory cytokines that correlate with histomorphology changes in the esophageal mucosa [40].

The study with participants with erosive, non-erosive esophagitis and controls evaluated endoscopic biopsies of the distal esophagus by biomarkers [platelet activation factor, IL-8, eotaxin 1, 2 and 3, macrophages protein inflammatory $1 \alpha$ and MCP-1]. Also, an increase in the expression of all inflammatory mediators in the biopsy obtained with erosive esophagitis when compared with GERD-NE and controls was observed [41]. But in data, we did not find a change in IL-8 immunoassayed cell levels compared to patients with and without endoscopic microerosions in high-definition digestive endoscopy coupled with NBI, considering the total number of immunoassayed cells and the number of immunoassayed cells per tissue area in esophageal biopsies.

Interleukin IL-6 expression has been studied in mucosal biopsies in patients with NERD and GERD. The result showed an increase in its expression compared to controls; however, no relationship was observed in the intensity of the endoscopic inflammation gradation [42]. In our study, no statistical difference occurred regarding total number of immunolabeled cells for IL- 6 and number of immunolabeled cells per tissue.

In general, long-term storage of paraffin blocks does not significantly affect immunohistochemical staining. At the literature is shown stable antigenicity of freshly cut sections of blocks that were up to six decades old, especially for cytoplasmic antigens. On the other hand, antigens located in the membrane and cell nuclei show a faster decay in immunostaining, with adequate preservation in up to a decade [43]. 
Assirati FS (2020) Screening of endoscopic microerosions in non-erosive esophagitis by high-definition digestive endoscopy coupled with narrow-band imaging and microerosions analysis by immunohistochemical, pHmetric and histology

The choice of the location level for esophageal biopsies was based on the fact that, in places close to SCJ, there could be a histological and immunohistochemical alteration caused by physiological gastroesophageal reflux. For this reason, the $2 \mathrm{~cm}$ level of SCJ was chosen. On the other hand, biopsies performed at more proximal levels would have a lower sensitivity for histological changes in GERD. The choice for performing "endoscopically normal" mucosal biopsies in the vicinity of the microerosions was that the tissue structure would be more preserved to define histological and immunohistochemical impairment.

In a systematic review to identify biomarkers for GERD using patients with normal endoscopy and excluding the use of conventional impedance- $\mathrm{pH}$ monitoring was concluded that there is no biomarker isolated for GERD, considering the multifactorial pathophysiology of this condition [44]. Finally, in the present study, with the methodology used, it was not possible to identify structural alterations between patients with and without microerosions. This finding could represent that microerosions would be an observation of random significance, possibly unimportant in the pathophysiology and evolution of GERD. Otherwise, the occurrence of microerosions could represent a very early picture in the evolution of the pathophysiology of GERD, which may partially explain the non-statistical significance of the results obtained.

\section{Perspective}

A new evaluation during a follow-up period should be done in current participant, including endoscopic microerosions analysis, with new biopsies. Moreover, the use of high-definition digestive endoscopy devices with magnification could improve the sensitivity in identifying minimal endoscopic changes, including microerosions. Finally, further studies with the identification of minimal endoscopic changes are possible with high-definition digestive endoscopic devices with magnification, together with the reflux type analysis by means of impedance-pHmetry, which may be complemented by evaluations of associations with histological changes such as dilation of intercellular spaces and also the expression of cell junction proteins. The constant progress in the field of artificial intelligence in the medical field, especially with the development of computational models, through image analysis tools previously stored in a database, we can assume that the identification of subtle endoscopic changes, such as minimal endoscopic changes in GERD may be more and better identified. With this new perspective, through deep learning analysis, esophageal images can be evaluated by multilayer textures, based on a historically accumulated set of illustration algorithms, opening a new field of GERD`s research.

\section{Conclusions}

The conclusions of our study were as follows:

- The presence of esophageal microerosions in high definition endoscopy exams with NBI in patients with typical symptoms of gastroesophageal reflux was a frequent finding, being observed in $42.9 \%$ of the study patients.

- Patients with oesophageal microerosions in high-definition endoscopy exams with NBI did not present statistically significant changes in the assessment of prolonged pH-metry, compared to patients without micro-erosions (controls).

- Histological and immunohistochemical evaluation of oesophageal biopsies in patients with oesophageal microerosions in highdefinition endoscopy exams with NBI did not show any statistically significant difference in relation to controls.

\section{References}

1. Moraes-Filho JP, Navarro-Rodriguez T, Barbuti RC, Eisig JN, Chinzon D, et al. (2010) Guidelines for the diagnosis and management of gastroesophageal reflux disease: an evidence-based consensus. Arq Gastroenterol 47: 99-115. [Crossref]

2. El-Serag HB, Sweet S, Winchester CC, Dent J (2014) Update on the epidemiology of gastro-oesophageal reflux disease: a systematic review. Gut 63: 871-880. [Crossref]

3. Katz OP, Gerson BL, Vela MF (2013) Guidelines for the diagnosis and management of gastroesophageal reflux disease. Am J Gastroenterol 108: 308-328. [Crossref]

4. Sandhu DS, Fass R (2018) Current trends in the management of gastroesophageal reflux disease. Gut Liver 12: 7-16. [Crossref]

5. Vaezi MF, Sifrim D (2018) Assessing old and new diagnostic tests for gastroesophageal reflux disease. Gastroenterology 154: 289-301. [Crossref]

6. Muthusamy VR, Lightdale JR, Acosta RD, Chandrasekhara V, Chathadi KV, et al (2015) The role of endoscopy in management of GERD. Gastrointest Endosc 81: 13051310. [Crossref]

7. Lundell LR, Dent J, Bennett JR, Blum AL, Armstrong D, et al. (1999) Endoscopic assessment of oesophagitis: clinical and functional correlates and further validation of the Los Angeles classification. Gut 45: 172-180. [Crossref]

8. Hunt A, Armstrong D, Katelaris P, Afihene M, Bane A, et al. (2017) World Gastroenterology Organization Global Guidelines- GERD global perspective on gastroesophageal reflux disease. J Clin Gastroenterol 51: 467-478. [Crossref]

9. Gyawali CP, Kahrilas PJ, Savarino E, Zerbib F, Mion F, et al. (2018) Modern diagnosis of GERD: the Lyon Consensus. Gut 67: 1351-1362. [Crossref]

10. Galloro G (2012) High technology imaging in digestive endoscopy. World $J$ Gastrointest Endosc 4: 22-27. [Crossref]

11. Naik RD, Evers L, Vaezi MF (2019) Advances in the diagnosis and treatment of GERD New tricks for an old disease. Curr Treat Options Gastroenterol 17: 1-17. [Crossref]

12. Rieder F, Cheng L, Harnett KM, Chak A, Cooper GS, et al. (2007) Gastroesophageal reflux disease-associate esophagitis induces endogenous cytokine production leading to motor abnormalities. Gastroenterology 132: 154-165. [Crossref]

13. Kandulski A, Malfertheiner P (2012) Gastroesophageal reflux disease-from reflux episodes to mucosal inflammation. Nat Rev Gastroenterol Hepatol 9: 15-22. [Crossref]

14. Souza RF, Huo X, Mittal V, Schuler CM, Carmack SW, et al. (2002) Gastroesophageal reflux may cause esophagitis through a cytokine - mediated mechanism, not by caustic (acid) injury. Gastroenterology 122: 299-307. [Crossref]

15. Souza RF, Huo X, Mittal V, Schuler CM, Carmack SW, et al. (2009) Gastroesophageal reflux might cause esophagitis through a cytokine-mediated mechanism rather than caustic acid injury. Gastroenterology 137: 1776-1784. [Crossref]

16. Cheng L, Cao W, Fiocchi C, Behar J, Biancani P, et al. (2006) HCl-induced inflammatory mediators in cat esophageal mucosa and inflammatory mediators in esophageal circular muscle in an in vitro model of esophagitis. Am J Physiol Gastrointest Liver Physiol 290: 1307-1317. [Crossref]

17. Yoshida N, Uchiyama K, Kuroda M, Sakuma K, Kokura S, et al. (2004) Interleukin-8 expression in the esophageal mucosa of patients with gastroesophageal reflux disease. Scand J Gastroenterol 39: 816-822. [Crossref]

18. Kandulski A, Wex T, Mönkemüller K, Kuester D, Fry LC, et al. (2010) Proteinaseactivated receptor-2 in the pathogenesis of gastroesophageal reflux disease. $\mathrm{Am} \mathrm{J}$ Gastroenterol 105: 1934-1943. [Crossref]

19. Richter JE (1997) Ambulatory esophageal pH Monitoring. Am J Med 103: 1305-1345. [Crossref]

20. Johnson LF, DeMeester TR (1986) Development of the 24 hours intra esophageal pH monitoring composite score system. J Clin Gastroenterol 8: 52-58. [Crossref]

21. Weusten BL, Roelofs JM, Akkermans LM, Van Berge-henegouwen GP, Smout AJ (1994) The symptom-association probability: an improved method for symptom analysis of 24-hour esophageal pH data. Gastroenterology 107: 1741-1745. [Crossref]

22. Sifrim D, Zerbib F (2012) Diagnosis and management of patients with reflux symptoms refractory to proton pump inhibitors. Gut 61: 1340-1354. [Crossref]

23. Bussmann C, Schoepfer AM, Safroneeva E, Haas N, Godat S, et al. (2016) Comparasion of different biopsy forceps models for tissue sampling in eosinophilic esophagitis. Endoscopy 48: 1069-1075. [Crossref] 
Assirati FS (2020) Screening of endoscopic microerosions in non-erosive esophagitis by high-definition digestive endoscopy coupled with narrow-band imaging and microerosions analysis by immunohistochemical, pHmetric and histology

24. Fiocca R, Mastracci L, Riddell R, Takubo K, Vieth M, et al. (2010) Development of consensus guidelines for the histologic recognition of microscopic esophagitis in patients with gastroesophageal reflux disease: The Esohisto Project. Human Pathol 41: 223-231. [Crossref]

25. Savarino E, Zentelin P, Mastracci L, Dulbecco P, Marabotto E, et al. (2013) Macroscopic esophagitis distinguishes patients with non erosive reflux disease from those with functional heartburn. $J$ Gastroenterol 48: 473-482. [Crossref]

26. Fitzgibbons PL, Bradley LA, Fatheree LA, Alsabeh R, Fulton RS, et al. (2014) Principles of analytic validation of immunohistochemical assays: guideline from the college of American Pathologists Pathology and Laboratory Quality center. Arch Pathol Lab Med 138: 1432-1443. [Crossref]

27. Hsu SM, Raine L, Fanger H (1981) Use of avidin-biotin-peroxidase complex (ABC) in immunoperoxidase techniques: a comparison between $\mathrm{ABC}$ and unlabeled antibody (PAP) procedures. J Histochem 29: 577-580. [Crossref]

28. Werneck-Silva AL, Pagliari C, Patzina RA, Takakura CFH, Duarte MI (2017) Esophageal mucosa in HIV infection: A"deeper" look at this little spoken organ. $J$ Gastroenterol Hepatol 32: 1832-1838. [Crossref]

29. Savarino E, de Bortolin N, de Cassan C, Della Coletta M, Bartolo O, et al. (2017) The natural history of gastroesophageal reflux disease: A comprehensive review. Dis Esophagus 30: 1-9. [Crossref]

30. Lei WY, Lin TT, Yi CH, Chen CL (2012) Disease characteristic in non-erosive reflux disease with and without endoscopically minimal change esophagitis: are they different? Digestion 85: 27-32. [Crossref]

31. Martinek J, Benes M, Hucl T, Drastich P, Stirand P, et al. (2008) Non-erosive and erosive gastroesophageal reflux diseases: No difference with regard to reflux pattern and motility abnormalities. Scand J Gastroenterol 43: 794-800. [Crossref]

32. Neto RML, Herbella FAM, Schlottmann F, Patti MG (2019) Does DeMeester score still define GERD? Dis Esophagus: 32. [Crossref]

33. Tseng PH, Chen CC, Chiu HM, Liao WC, Wu MS, et al. (2011) Performance of narrow band imaging and magnification endoscopy in the prediction of therapeutic response in patients with gastroesophageal reflux disease. J Clin Gastroenterol 45: 501-506. [Crossref]

34. Albuquerque W, Coelho LGV, Savassi-Rocha PR, Poncinelli CS, da Rocha LCM, et al. (2007) Endoscopic and histological correlation of the finding of mucosa of the distal esophagus in Non erosive reflux disease. Esophagus 4: 53-58.
35. Lee YC, Lin JT, Chiu HM, Liao WC, Chen CC, et al. (2007) Intraobserver and interobserver consistency for grading esophagitis with narrow band imaging. Gastrointest Endosc 66: 230-236. [Crossref]

36. Arul P, Vinoth B, Alexander T, Phansalkar M, Padhi S (2015) Correlation of narrow band imaging endoscopy and histopathology in the diagnosis of nonerosive reflux disease. Saudi J Gastroenterol 21: 330-336. [Crossref]

37. Gabbard SL, Fass R, Maradey-Romero C, Belfer RG, Dickman R (2016) Identifyng minimal changes in nonerosive reflux diseases. Is the pay worth the labor? $J$ Clin Gastroenterol 50: 11-16. [Crossref]

38. Isomoto H, Wang A, Mizuta Y, Akazawa Y, Ohba K, et al. (2003) Elevated levels of chemokines in esophageal mucosal of patients with reflux esophagitis. $\mathrm{Am} J$ Gastroenterol 98: 551-556. [Crossref]

39. Isomoto H, Saenko VA, Kanazawa Y, Nishi Y, Ohsturu A, et al. (2004) Enhanced expression of interleukin-8 and activation of nuclear factor kappa-B in endoscopy negative gastroesophageal disease. Am J Gastroenterol 99: 589-597. [Crossref]

40. Mönkemüller K, Wex T, Kuester D, Fry L, Peitz U, et al. (2009) Interleukin 1- $\beta$ and interleukin-8 expression correlate with the histomorphological changes in esophageal mucosa of patients with erosive and non-erosive reflux disease. Digestion 79: 186-195. [Crossref]

41. Altomare A, Ma J, Guarino MPL, Cheng L, Rieder F, et al. (2012) Platelet-activating factor and distinct chemokines are elevated in mucosal biopsies of erosive compared with non-erosive reflux disease patients and controls. Neurogastroenterol Motil 24: 943-e463. [Crossref]

42. Yoshida N (2007) Inflammation and oxidative stress in gastroesophageal reflux disease. J Clin Biochem Nutr 40: 13-23. [Crossref]

43. Grillo F, Bruzzone M, Pigozzi S, Prosapio S, Migliora P, et al. (2017) Immunohistochemestry on old archival paraffin blocks: is there an expire date? $J$ Clin Pathol 70: 988-993. [Crossref]

44. Kia L, Pandolfino JE, Kahrilas PJ (2016) Biomarkers of reflux disease. Clinical Gastroenteol and Hepatol 14: 790-797. [Crossref]

Copyright: $\odot 2020$ Assirati FS. This is an open-access article distributed under the terms of the Creative Commons Attribution License, which permits unrestricted use, distribution, and reproduction in any medium, provided the original author and source are credited. 